\section{Optimization of Ion Millers For TEM Sample Preparation}

Past and present members of the Center for Microanalysis of Materials, University of Illinois

Ion millers are a pain in the neck! They are designed to remove material from the sample. This means: a) that they always remove material from other places too and b) that the material gets deposited somewhere else. The result of this is that ion millers are inevitably high-maintenance instruments.

Therefore it is important to make the most of them when they are in operation. To aid in this quest, two things can be helpful: to get the beam well aligned and to know the milling rate.

An ion gun, however powerful the beam it produces, is of no use if the beam misses the sample. A means of checking the alignment is therefore of great importance.

We have found that the best way of checking the alignment depends on the miller in question. On the older millers, which have a rather broad ion beam and where it is not easy to see the sample during milling, the preferred method is to use anodized tantalum - sample details given below. With the rotation of the sample turned off, a short period of milling produces a colored spot on the sample which reveals both the position of the ion beam and the speed of milling

On newer millers, where the ion beam is smaller and where the sample can be observed during the milling, we have found that the best way of checking alignment is to use a piece of glass. The glass luminesces in the ion beam and so shows a bright spot where the beam hits. The advantage of using glass (in an ion miller which mills both top and bottom of the sample) is that both beams can be located. The luminescence can be seen through the glass. The recipe (which comes from Fischione) is to use a microscope cover slip, cut to $3 \mathrm{~mm}$ diameter with an ultrasonic cutter or by other means.

This is not the end of the story, however. We have found that ion guns which are operating at nominally the same parameters (voltage, current, etc.) may not produce equal milling rates. Who knows why? Therefore it is also useful to have a quantitative way to monitor the actual milling rate. Of course, different samples mill at different rates but it is convenient to have a standard by which things can be compared.

For this we use anodized tantalum (other metals would probably do as well). Anodized metals have very characteristic colors which result from interference between light reflected at the surface of the oxide and the light reflected at the surface of the metal underneath. The color depends on the thickness of the oxide. The starting thickness depends on the voltage of the oxidation. After a short period of ion milling, a piece of anodized tantalum shows a series of concentric colored rings - where the oxide has been thinned. By observing how long it takes for a particular

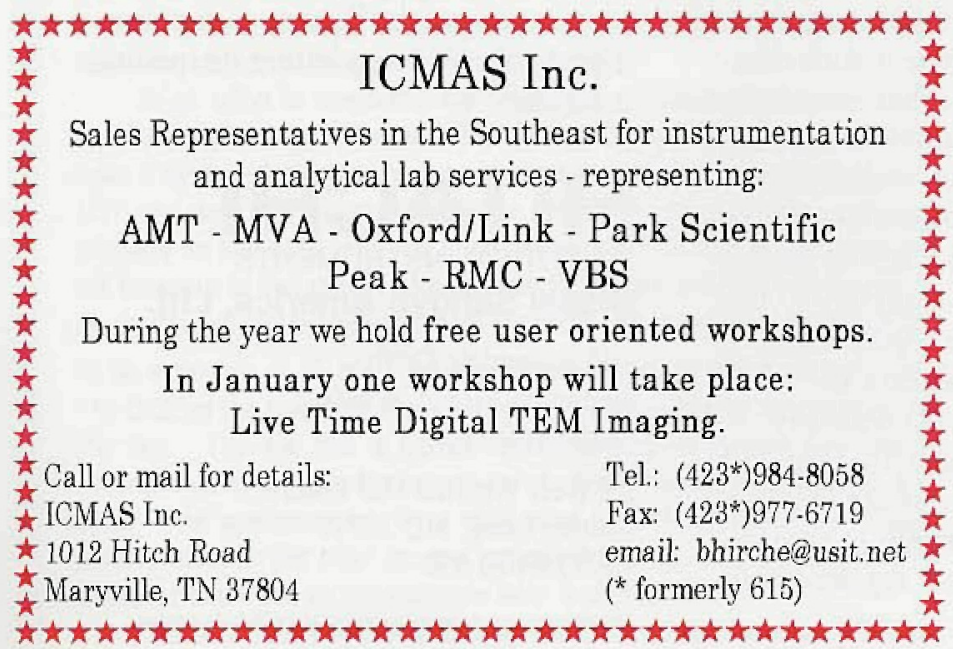

color sequence to develop it is possible to assess the relative milling speed of the instrument. The absolute speed could also be measured from a calibration, of course, but we have not found this so helpful. Since different samples mill at different speeds anyway, a relative value is generally sufficient.

\section{More on Anodizing}

For those who are not familiar with anodizing, here are some more detailed notes on the procedure. Anodizing is an electrochemical procedure, as are electropolishing and electroplating. In each case, the sample forms one electrode in an electrochemical cell. In the case of anodizing, the conditions are chosen so that the effect is to grow an oxide on the surface of the metal.

The cell is a beaker of a suitable solution into which two electrodes are placed. One of the electrodes is the sample and the other is a piece of any handy metal. Stainless steel is often used. A voltage is applied between the electrodes.

To anodize tantalum, the solution can be almost anything which conducts. A pinch of salt in water will do just fine. The only trick to note is that, if there are fluoride ions in the solution, the oxide will peel off quite easily (for example, with Scotch tape), but, if there are no fluoride ions, the oxide will adhere tenaciously to the metal. Thus, for normal purposes it is desirable to avoid fluorides while, if you want to get back to the clean metal for any reason, it is easy to do so by anodizing in, say, sodium fluoride.

The thickness of the oxide is quite closely, linearly proportional to the voltage applied. The oxide grows quickly and reaches a saturation thickness within a few seconds - the saturation thickness is the one to use. A colorl voltage sequence folllows:

$\begin{array}{ll}\text { Voltage } & \text { Color } \\ 0-10 & \text { metallic } \\ 20 & \text { pale gold } \\ 25-30 & \text { strong gold } \\ 35-40 & \text { strong blue-purple } \\ 50 & \text { pale blue } \\ 60 & \text { metallic } \\ 70-75 & \text { yellow-gold } \\ 80-85 & \text { strong reddish-gold } \\ 90 & \text { red-purple } \\ 95 & \text { blue-purple } \\ 100-105 & \text { blue } \\ 110 & \text { pale green } \\ 115 & \text { yellow } \\ 120 & \text { salmon } \\ 125-130 & \text { rose } \\ 135 & \text { grey }\end{array}$

These are the colors of dry samples in air. Under water the colors are quite different.

This information needs to be qualified. The colors are not exactly reproducible. In particular, the colors seem to change for the same piece of tantalum if it is anodized repeatedly. This may be the effect of the roughening of the surface produced by the ion milling. It may also become difficult to strip the metal clean following anodization in the presence of fluoride ions after several cycles of anodization. Roughening would also explain this.

\section{Additional note regarding cold stages on ion millers}

For many kinds of samples, it is desirable to do the ion milling with the sample at low temperature. The milling process puts a lot of energy into the sample (especially in the newer, faster millers), and this energy can cause major undesired changes in the specimen. The cooling of the stage typically moves the sample with respect to the ion guns. This means that the alignment of the beams is affected (often dramatically) by the cooling. To be sure that the correct alignment is achieved, it is necessary to work (both to align the miller and to do the milling) with the stage fully cooled to a stable temperature. This can take a long time. The time will vary for one design to another and can be as much as an hour. It is very frustrating but it is necessary to have great patience. Starting to mill before the sample is cold will not help - the beams will miss the sample, other parts of the miller will be worn out more quickly and the miller will require service sooner. 

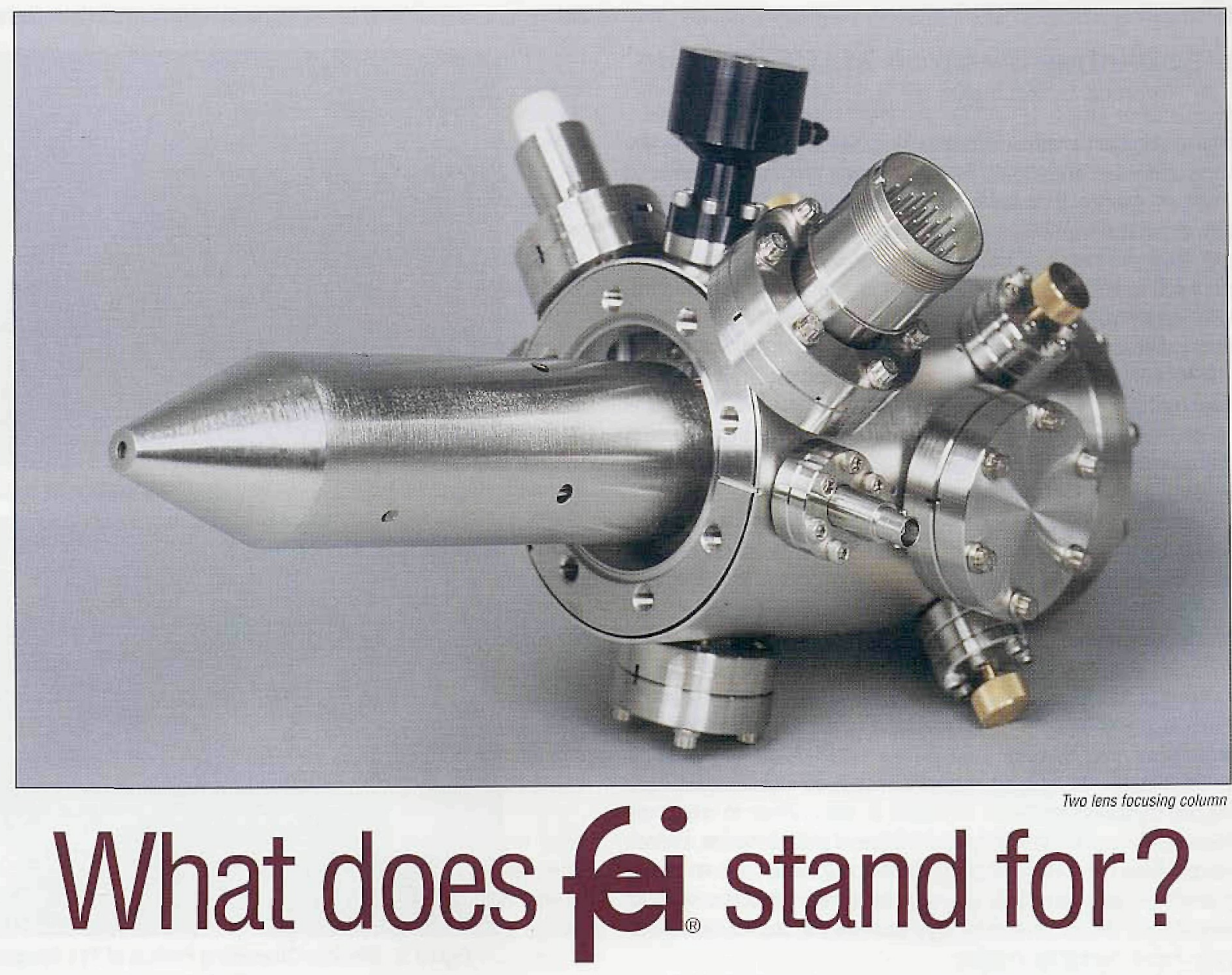

Our compact, UHV, field emission columns are used by researchers world wide. Innovative electrostatic optics and dedicated electronics allow you to integrate a high current density electron or ion column into most vacuum systems. FEI also supplies researchers with other specialized products...

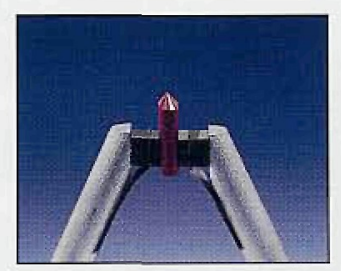

\section{$\mathrm{LaB}_{6}$ an $\mathrm{CeB} 6$ Cathodes}

FEl's Mini-Vogel Mount, the first universally compatible Iong-life, high-stability LaB6 cathode, provides excellent performance and the best cost-per-use value for installation into your EM systems.

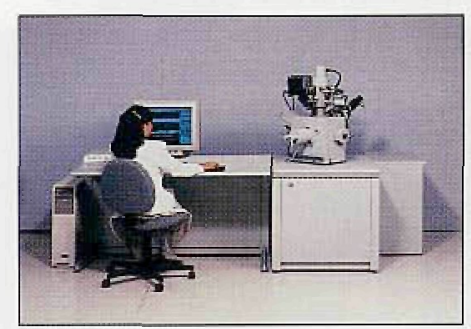

\section{FIB Workstations}

Focused ion beam micromilling workstations range from the 8"-wafer compatible model to the economical 2" small sample model ideal for semiconductor, biological, TEM, and MEMS specimens.

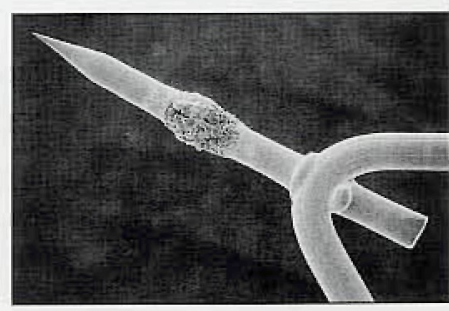

Field Emission Cathodes

FEl supplies Schottky field emitters to EM manufacturers worldwide. Schottky emission's high current intensity has established it as the preferred electron source for high resolution SEM, TEM, Auger, ESCA, EDX, and lithography.

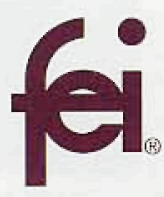

FEl Company

7451 NE Evergreen Parkway

Hillsboro, OR $97124-5830$

(503) 640-7500 Fax (503) 640-7509

email:rsk@feico.com

Now, when you think of FEI, you'll know we are the Specialists in Field Electron and Ion Technology. 